\title{
Mucous gland enlargement in chronic bronchitis : Extent of enlargement in the tracheo-bronchial tree
}

\author{
G. L. RESTREPO ${ }^{1}$ A N D B E E HEA R D \\ From the Department of Pathology, Postgraduate Medical School of London
}

One of the pathological features of chronic bronchitis is enlargement of the bronchial mucous glands. Reid (1960a and b) measured the thickness of the glands in various random bronchi and reported a linear increase in chronic bronchitis. We have recently supported Reid by reporting an increased area of glands in transverse bronchial sections in chronic bronchitis using a different method (Restrepo and Heard, 1963).

It is often assumed that bronchial gland enlargement in chronic bronchitis is uniform throughout the tracheo-bronchial tree. There is no justification for such an assumption and, in fact, there were differences in the degree of enlargement between our initial two sampled sites. We have now taken a large number of samples from the trachea and main, lobar, and segmental bronchi, and have determined the extent of this variation. No bronchi distal to the segmental ones were examined, but all the sampled sites usually showed some degree of gland enlargement in chronic bronchitis.

1 British Council Scholar

\section{MATERIAL AND METHODS}

Eight adult males were selected on account of reliable clinical histories of the presence or absence of cough with sputum continuously for more than two years (Ciba Guest Symposium, 1959). The four control patients denied having a cough or producing sputum. The four bronchitics all had a cough and had produced at least half a cupful of sputum daily for over 10 years. All were disabled to some extent (see Table I) and all died directly as a result of pulmonary disease, although one patient also had carcinoma of the prostate.

The trachea and lungs were fixed intact by perfusing formalin into the main pulmonary artery at a pressure of 25 to $30 \mathrm{~cm}$. formalin for 72 hours. This route of perfusion was chosen to reduce the tendency of the autolysed mucosal surface epithelium of the bronchi to wash off when fluid was run directly in. The perfusing apparatus has been described previously (Heard, 1960).

Samples were taken from 36 sites in the trachea and main, lobar, and segmental bronchi (Fig. 1). Transverse blocks were embedded in paraffin, stained with haematoxylin and eosin, and projected on thin white card at a magnification of 10 diameters. The

TABLE I

\begin{tabular}{|c|c|c|c|c|c|c|c|c|c|}
\hline Case & File No. & Sex & $\begin{array}{l}\text { Age } \\
(y r .)\end{array}$ & $\begin{array}{l}\text { Height } \\
(\text { ft.in. })\end{array}$ & $\begin{array}{l}\text { Weight } \\
\text { (st. lb.) }\end{array}$ & $\begin{array}{l}\text { Amount of } \\
\text { Sputum } \\
\text { per Dav }\end{array}$ & $\begin{array}{l}\text { Duration } \\
\text { of Sputum } \\
\text { Production } \\
\quad(y r .)\end{array}$ & $\begin{array}{l}\text { Dyspnoea } \\
\text { Duration } \\
(y r .)\end{array}$ & $\begin{array}{l}\text { Cause of } \\
\text { Death }\end{array}$ \\
\hline 1 & P.M. 9932 & M & 70 & 57 & 910 & \multirow{3}{*}{\multicolumn{2}{|c|}{$\begin{array}{l}\text { No chronic respiratory } \\
\text { symptoms }\end{array}$}} & & \multirow{7}{*}{$\begin{array}{l}\text { Nephrotic syndrome } \\
\text { due to tubular necrosis } \\
\text { Nephrotic syndrome } \\
\text { due to membranous } \\
\text { glomerulonephritis } \\
\text { Peritonitis from } \\
\text { lymphosarcoma of } \\
\text { jejunum } \\
\text { Myocardial infarction } \\
\text { Respiratory failure and } \\
\text { carcinoma of prostate } \\
\text { Respiratory failure and } \\
\text { cor pulmonale } \\
\text { Respiratory failure and } \\
\text { cor pulmonale } \\
\text { Respiratory failure and } \\
\text { cor pulmonale }\end{array}$} \\
\hline 2 & P.M. 9936 & $\mathbf{M}$ & 42 & 57 & 104 & & & & \\
\hline 3 & P.M. 9942 & $\mathbf{M}$ & 62 & 52 & 52 & & & & \\
\hline $\begin{array}{l}4 \\
5\end{array}$ & $\begin{array}{l}\text { P.M. } 9943 \\
\text { P.M. } 9926\end{array}$ & $\begin{array}{l}\mathrm{M} \\
\mathbf{M}\end{array}$ & $\begin{array}{l}66 \\
73\end{array}$ & $\begin{array}{ll}5 & 4 \\
5 & 4\end{array}$ & $\begin{array}{rr}14 & 4 \\
9 & 2\end{array}$ & 1 cup & 40 & 40 & \\
\hline 6 & P.M. 9937 & $\mathbf{M}$ & 61 & 56 & 1111 & $\frac{1}{2}$ cup & 10 & 5 & \\
\hline 7 & P.M. 9970 & $\mathbf{M}$ & 49 & 510 & 1210 & $\frac{1}{2}$ cup & 45 & 20 & \\
\hline 8 & P.M. 9987 & $\mathbf{M}$ & 54 & 510 & 114 & $\frac{1}{2}$ cup & 30 & 3 & \\
\hline
\end{tabular}




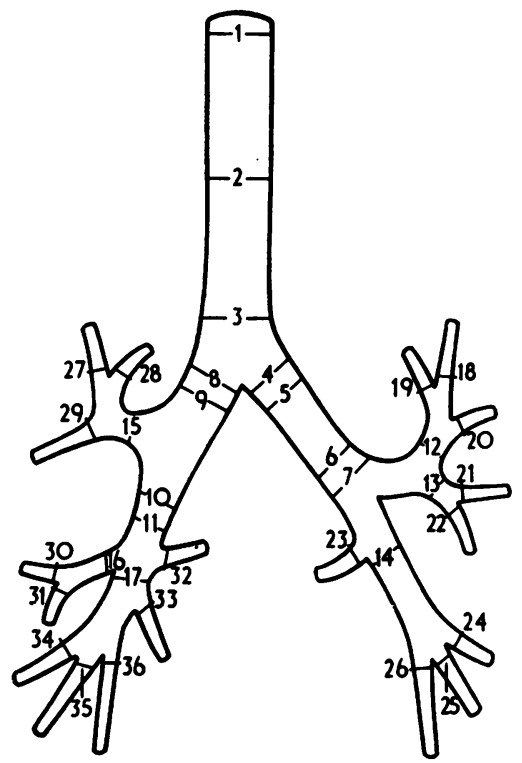

FIG. 1. Diagram of tracheo-bronchial tree showing sites sampled. Sites 19, 26, 28, and 36 are on posterior bronchi.

bronchial wall and glands were traced in pencil, cut out, and weighed as described previously (Restrepo and Heard, 1963). The area of the glands was calcu- lated from these weights. No correction factor was used to allow for shrinkage in processing.

\section{RESULTS}

The average gland areas of the four bronchitics were greater than those of the four controls at all except one of the 36 sites sampled (see Table II). This confirms and extends our previous findings using only two sites (Restrepo and Heard, 1963). The extent of the glandular enlargement is illustrated diagrammatically in Fig. 2 , being present on both lungs all the way from the top of the trachea to the segmental bronchi. (A statistical analysis is described below.)

Referring to Fig. 3, it will be seen that the area of normal glands in square millimetres diminishes fairly steadily towards the smaller bronchi. In bronchitics, the shape of the graph is much the same but at a higher level (Fig. 4), indicating the fairly uniform and overall pattern of gland enlargement.

We noted previously that, although there was remarkable gland enlargement in chronic bronchitics as a group, half of the readings overlapped with controls. Hence we pointed out that chronic bronchitis could not always be diagnosed on one measurement alone. In the present series,

TABLE II

AREA (MM. ${ }^{2}$ ) OF THE BRONCHIAL MUCOUS GLANDS AT 36 SITES IN FOUR CONTROLS AND FOUR BRONCHITICS Controls

\begin{tabular}{|c|c|c|c|c|c|c|c|c|c|c|}
\hline & & & & & & & & & & \\
\hline Site & 1 & 2 & 3 & 4 & Mean & 5 & 6 & 7 & 8 & Mean \\
\hline $\begin{array}{r}1 \\
2 \\
3 \\
4 \\
5 \\
6 \\
7 \\
8 \\
9 \\
10 \\
11 \\
12 \\
13 \\
14 \\
15 \\
16 \\
17 \\
18 \\
19 \\
20 \\
21 \\
22 \\
23 \\
24 \\
25 \\
26 \\
27 \\
28 \\
29 \\
30 \\
31 \\
32 \\
33 \\
34 \\
35 \\
36\end{array}$ & $\begin{array}{r}18 \cdot 20 \\
18 \cdot 76 \\
17 \cdot 60 \\
18 \cdot 48 \\
12 \cdot 80 \\
14 \cdot 08 \\
12 \cdot 56 \\
7 \cdot 12 \\
13 \cdot 76 \\
12 \cdot 60 \\
13 \cdot 40 \\
5 \cdot 28 \\
8 \cdot 08 \\
8 \cdot 16 \\
3 \cdot 20 \\
9 \cdot 60 \\
9 \cdot 12 \\
1 \cdot 92 \\
2 \cdot 48 \\
3 \cdot 60 \\
2 \cdot 60 \\
2 \cdot 00 \\
8 \cdot 00 \\
1 \cdot 96 \\
1 \cdot 60 \\
4 \cdot 92 \\
2 \cdot 64 \\
4 \cdot 28 \\
4 \cdot 24 \\
5 \cdot 52 \\
5 \cdot 20 \\
7 \cdot 44 \\
6 \cdot 12 \\
2 \cdot 96 \\
3 \cdot 60 \\
1 \cdot 32\end{array}$ & $\begin{array}{r}12.60 \\
19.24 \\
16.24 \\
14.64 \\
13.40 \\
12.28 \\
17.60 \\
10.36 \\
11.96 \\
9.36 \\
10.44 \\
7.68 \\
5.60 \\
4.88 \\
6.52 \\
1.80 \\
7.20 \\
1.48 \\
1.12 \\
1.64 \\
1.20 \\
1.88 \\
2.00 \\
1.64 \\
3.48 \\
2.80 \\
1.52 \\
3.96 \\
1.48 \\
3.12 \\
5.00 \\
1.92 \\
3.16 \\
4.08 \\
1.52 \\
4.48\end{array}$ & 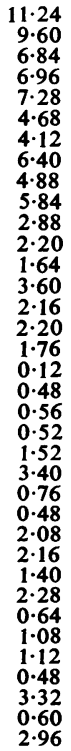 & $\begin{array}{r}13 \cdot 92 \\
29 \cdot 88 \\
16 \cdot 24 \\
22 \cdot 40 \\
14 \cdot 24 \\
17 \cdot 92 \\
17 \cdot 24 \\
18 \cdot 40 \\
17 \cdot 28 \\
12 \cdot 80 \\
17 \cdot 68 \\
4 \cdot 40 \\
5 \cdot 20 \\
9 \cdot 20 \\
5 \cdot 92 \\
7 \cdot 88 \\
6 \cdot 00 \\
1 \cdot 00 \\
1 \cdot 84 \\
1 \cdot 76 \\
1 \cdot 40 \\
0 \cdot 16 \\
4 \cdot 60 \\
4 \cdot 12 \\
3 \cdot 12 \\
2 \cdot 80 \\
2 \cdot 72 \\
3 \cdot 36 \\
4 \cdot 80 \\
3 \cdot 88 \\
2 \cdot 12 \\
3 \cdot 00 \\
1 \cdot 64 \\
2 \cdot 68 \\
1 \cdot 08 \\
4 \cdot 84\end{array}$ & 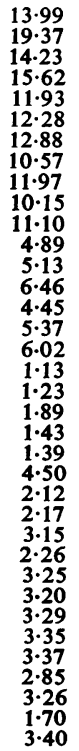 & $\begin{array}{r}20 \cdot 80 \\
11 \cdot 56 \\
16 \cdot 24 \\
37 \cdot 16 \\
11 \cdot 72 \\
18 \cdot 24 \\
25 \cdot 60 \\
33 \cdot 80 \\
34 \cdot 28 \\
10 \cdot 16 \\
14 \cdot 80 \\
9 \cdot 60 \\
6 \cdot 24 \\
16 \cdot 20 \\
14 \cdot 52 \\
10 \cdot 40 \\
15 \cdot 28 \\
2.48 \\
1 \cdot 28 \\
5.96 \\
1.48 \\
1 \cdot 20 \\
7 \cdot 56 \\
0.40 \\
1.92 \\
3.00 \\
2.52 \\
4.12 \\
5 \cdot 36 \\
5.96 \\
1 \cdot 16 \\
5 \cdot 28 \\
3.72 \\
2.48 \\
2.56 \\
1 \cdot 40\end{array}$ & $\begin{array}{r}29 \cdot 96 \\
34 \cdot 76 \\
32 \cdot 32 \\
23 \cdot 48 \\
18 \cdot 88 \\
19 \cdot 76 \\
19 \cdot 20 \\
40 \cdot 64 \\
32 \cdot 04 \\
25 \cdot 84 \\
19 \cdot 44 \\
15 \cdot 80 \\
6 \cdot 52 \\
9 \cdot 80 \\
11 \cdot 92 \\
10 \cdot 24 \\
12 \cdot 96 \\
3 \cdot 96 \\
9 \cdot 44 \\
3 \cdot 12 \\
3 \cdot 80 \\
1 \cdot 92 \\
18 \cdot 76 \\
12 \cdot 80 \\
6 \cdot 60 \\
11 \cdot 12 \\
9 \cdot 64 \\
4 \cdot 16 \\
10 \cdot 88 \\
4 \cdot 56 \\
4 \cdot 72 \\
11 \cdot 24 \\
4 \cdot 60 \\
9 \cdot 12 \\
13 \cdot 84 \\
5 \cdot 12\end{array}$ & $\begin{array}{r}20 \cdot 64 \\
25 \cdot 92 \\
22 \cdot 28 \\
19 \cdot 64 \\
27 \cdot 48 \\
20 \cdot 00 \\
29 \cdot 68 \\
18 \cdot 24 \\
27 \cdot 60 \\
18 \cdot 40 \\
10 \cdot 88 \\
16 \cdot 00 \\
18 \cdot 52 \\
14 \cdot 72 \\
11 \cdot 12 \\
3 \cdot 48 \\
14 \cdot 96 \\
5 \cdot 00 \\
3 \cdot 84 \\
13 \cdot 96 \\
10 \cdot 00 \\
11 \cdot 08 \\
13 \cdot 96 \\
7 \cdot 44 \\
9 \cdot 64 \\
9 \cdot 56 \\
2 \cdot 20 \\
0 \cdot 88 \\
2 \cdot 88 \\
4 \cdot 56 \\
5 \cdot 92 \\
19 \cdot 00 \\
2 \cdot 04 \\
2 \cdot 48 \\
3 \cdot 40 \\
5 \cdot 72\end{array}$ & $\begin{array}{r}15 \cdot 28 \\
15 \cdot 40 \\
15 \cdot 28 \\
14 \cdot 32 \\
17 \cdot 44 \\
28 \cdot 80 \\
28 \cdot 68 \\
24 \cdot 44 \\
19 \cdot 92 \\
19 \cdot 00 \\
9 \cdot 16 \\
5 \cdot 56 \\
5 \cdot 60 \\
9 \cdot 60 \\
15 \cdot 92 \\
9 \cdot 20 \\
9 \cdot 36 \\
5.00 \\
4 \cdot 68 \\
3.00 \\
4.60 \\
6 \cdot 08 \\
11 \cdot 88 \\
8 \cdot 96 \\
5 \cdot 12 \\
2.72 \\
5 \cdot 56 \\
2 \cdot 16 \\
16 \cdot 28 \\
4.68 \\
4 \cdot 52 \\
10 \cdot 56 \\
2 \cdot 80 \\
7 \cdot 28 \\
5 \cdot 04 \\
10 \cdot 72\end{array}$ & $\begin{array}{r}21 \cdot 67 \\
21 \cdot 91 \\
21 \cdot 53 \\
23 \cdot 65 \\
18 \cdot 88 \\
21 \cdot 70 \\
25 \cdot 54 \\
29 \cdot 28 \\
28 \cdot 46 \\
18 \cdot 35 \\
13 \cdot 57 \\
11 \cdot 74 \\
9 \cdot 22 \\
12 \cdot 58 \\
13 \cdot 37 \\
8 \cdot 33 \\
13 \cdot 14 \\
4 \cdot 11 \\
4 \cdot 81 \\
6 \cdot 51 \\
4 \cdot 97 \\
5 \cdot 07 \\
13 \cdot 04 \\
7 \cdot 40 \\
5 \cdot 82 \\
6 \cdot 60 \\
4 \cdot 98 \\
2 \cdot 83 \\
8 \cdot 85 \\
4 \cdot 94 \\
4 \cdot 08 \\
11 \cdot 52 \\
3 \cdot 29 \\
5 \cdot 34 \\
6 \cdot 21 \\
5 \cdot 74\end{array}$ \\
\hline
\end{tabular}

\section{Bronchitics}



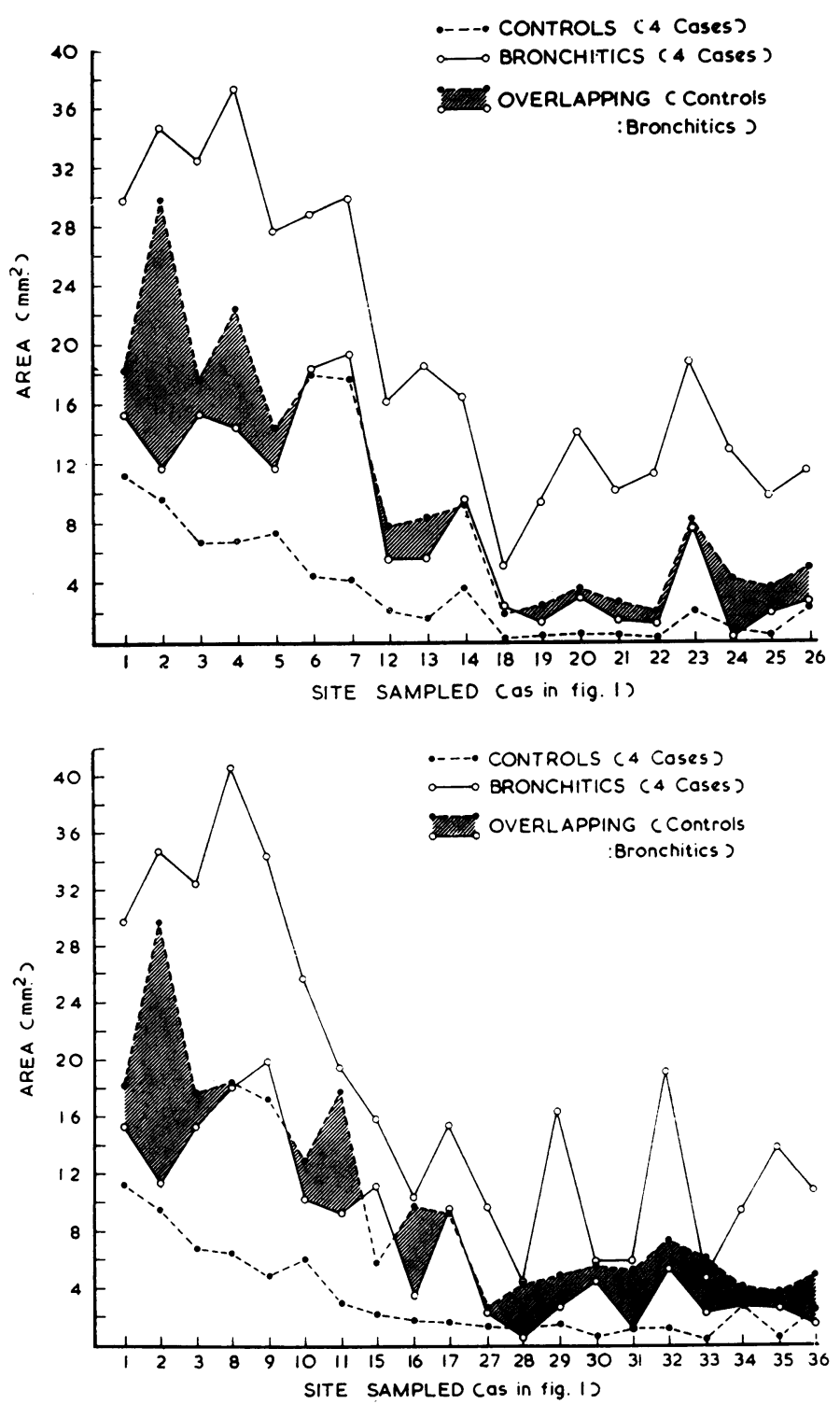

FIG. 2. Graphs showing overlap (shaded) between controls and brorchitics when the full range of areas at various sites in the trachea and bronchi of the lung are compared: (above) left lung; (below) right lung. The overlap is present in most sites.

there was some overlap of the bronchitic and control values, from the top of the trachea down to the segmental bronchi (Fig. 2). The overlap was present in 28 sites and was occasionally complete. It was absent in eight sites.

Among the controls, case 3 showed lower readings than the others in most sites. The patient died from a lymphosarcoma of the jejunum, steatorrhoea, and extreme cachexia (weight 5 st. $2 \mathrm{lb}$. at necropsy) which may relate in some way to the smallness of the glands.

A statistical analysis was carried out (Table III). Logarithms of weights of cut-out pieces of card corresponding to glands were used for most of the analysis since logarithms appeared to be more 'normally' distributed than the weights themselves. There was statistical support for the evidence that gland areas are greater in bronchitics than in controls $(5 \%$ significant, line 1 in Table III). This was the case despite the fact that the areas of mucous glands differed statistically from one person to another, in both controls and bronchitics ( $1 \%$ significant, line 6 in Table III).

In order to find out if the degree of gland enlargement varied in different parts of the tracheobronchial tree, we divided the 36 sites into five groups for comparison (Fig. 5): trachea, left and right main bronchi, left and right lobar bronchi. left segmental bronchi, and right segmental bronchi. The difference between bronchitics and controls varied from one group of sites to another $(1 \%$ significant, line 4 in Table III). This difference, however, did not vary significantly from site to site within each of the above groups (line 5 in Table III). It was also noticeable that the difference between mean logarithms of weights of bronchitics and controls was greatest in that group where the glands weighed the least, i.e., in segmental bronchi (Fig. 6A and B). When the actual difference in area in square millimetres between bronchitics and controls was studied, it was found that they remained roughly constant in all groups but one, being greater in the main bronchi (Fig. $6 \mathrm{C}$ ). The practical meaning of these findings is discussed below.

There was a greater increase in gland area in bronchitis in the left segmental bronchi than in the 
right. This was significant when logarithms were compared. It was noticed, however, from inspection of the data, that the variation from site to site was greater on the right than on the left and that there was some overlap.

\section{DISCUSSION}

The assumption that enlargement of the bronchial glands in chronic bronchitis is uniform throughout the tracheo-bronchial tree has been shown in the present article and in a previous one to be incorrect. We previously reported a series of 15 bronchitics and eight controls sampled at two sites in the left lung (Restrepo and Heard, 1963) and showed that, on average, bronchitics tended to have larger gland areas. However, the degree of gland enlargement differed from one bronchitic to another and caused us to suspect irregularities in the regional distribution of gland enlargement in individual cases.

In the new series reported here, gland enlargement in bronchitis involved the whole trachea, both main bronchi, all lobar bronchi, and all segmental bronchi (at which level our measurements terminated), but there was variation from part to part and from case to case.

In order to compare gland enlargement in main and segmental bronchi we added together the areas of all the segmental bronchi of controls and compared them with a similar total in bronchitics. We found that the increase in actual area at those sites in bronchitics was less than in the main bronchi supplying them. At first sight, this would right lung.
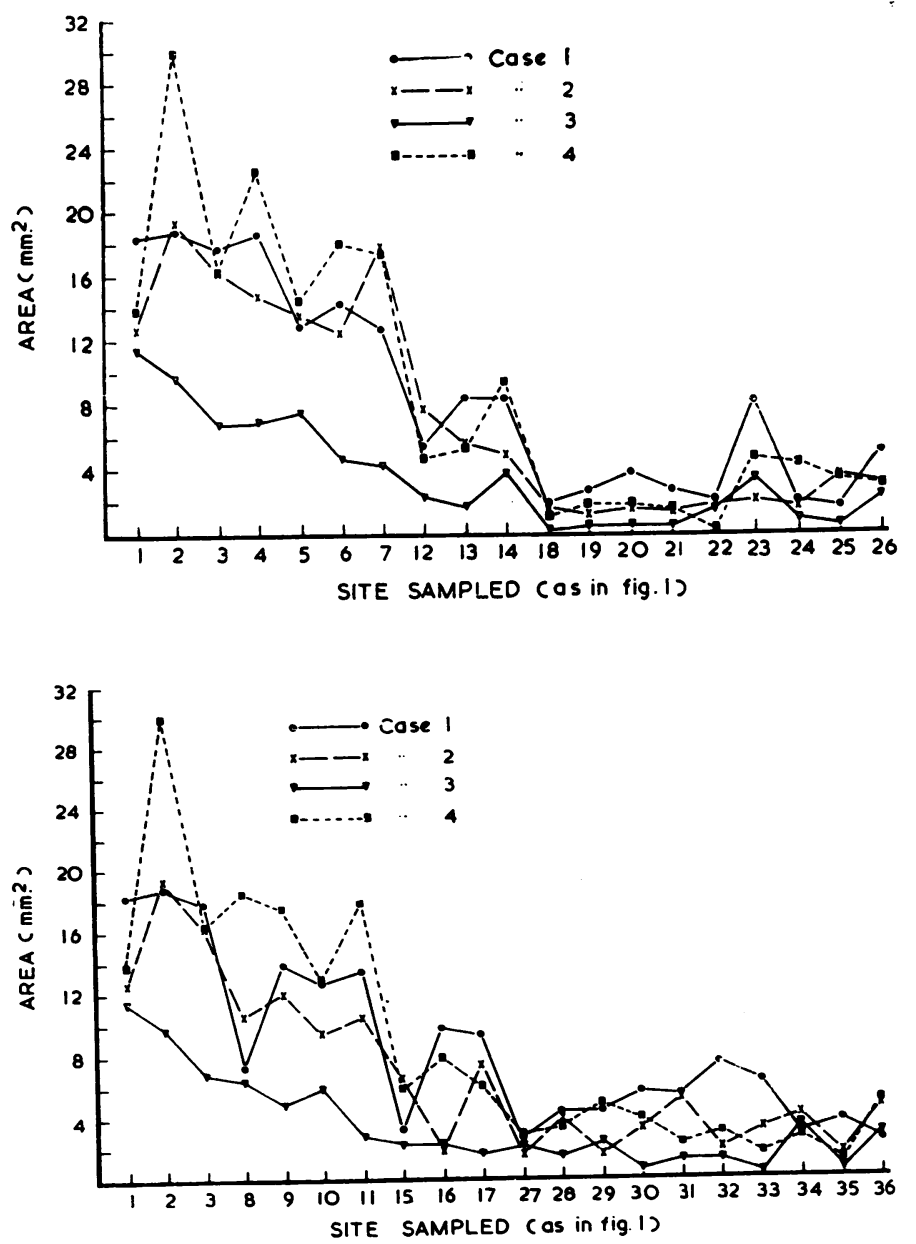

FIG. 3. Graphs showing areas of glands at various sites in the trachea and bronchi of the lung in four control cases: (above) left lung; (below)

seem to suggest that most of the mucus was derived from the main rather than from the peripheral bronchi, but the opposite is more probable because there are many more glands on

T A B L E I I I

STATISTICAL RESULTS

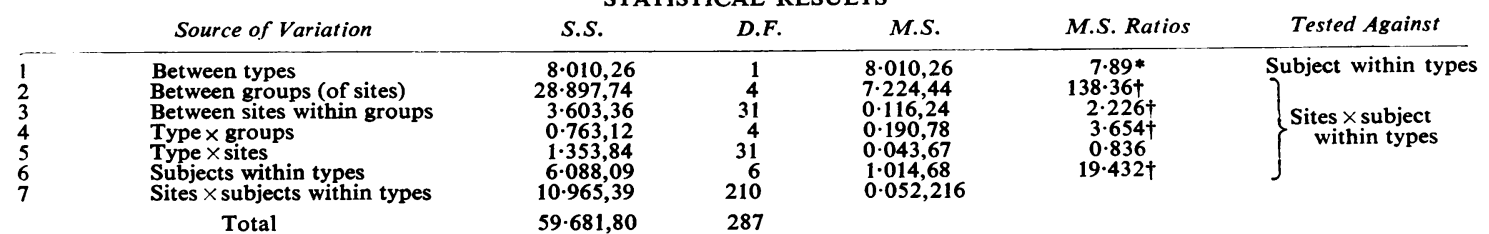

* Denotes $5 \%$ significance. † Denotes $1 \%$ significance. 

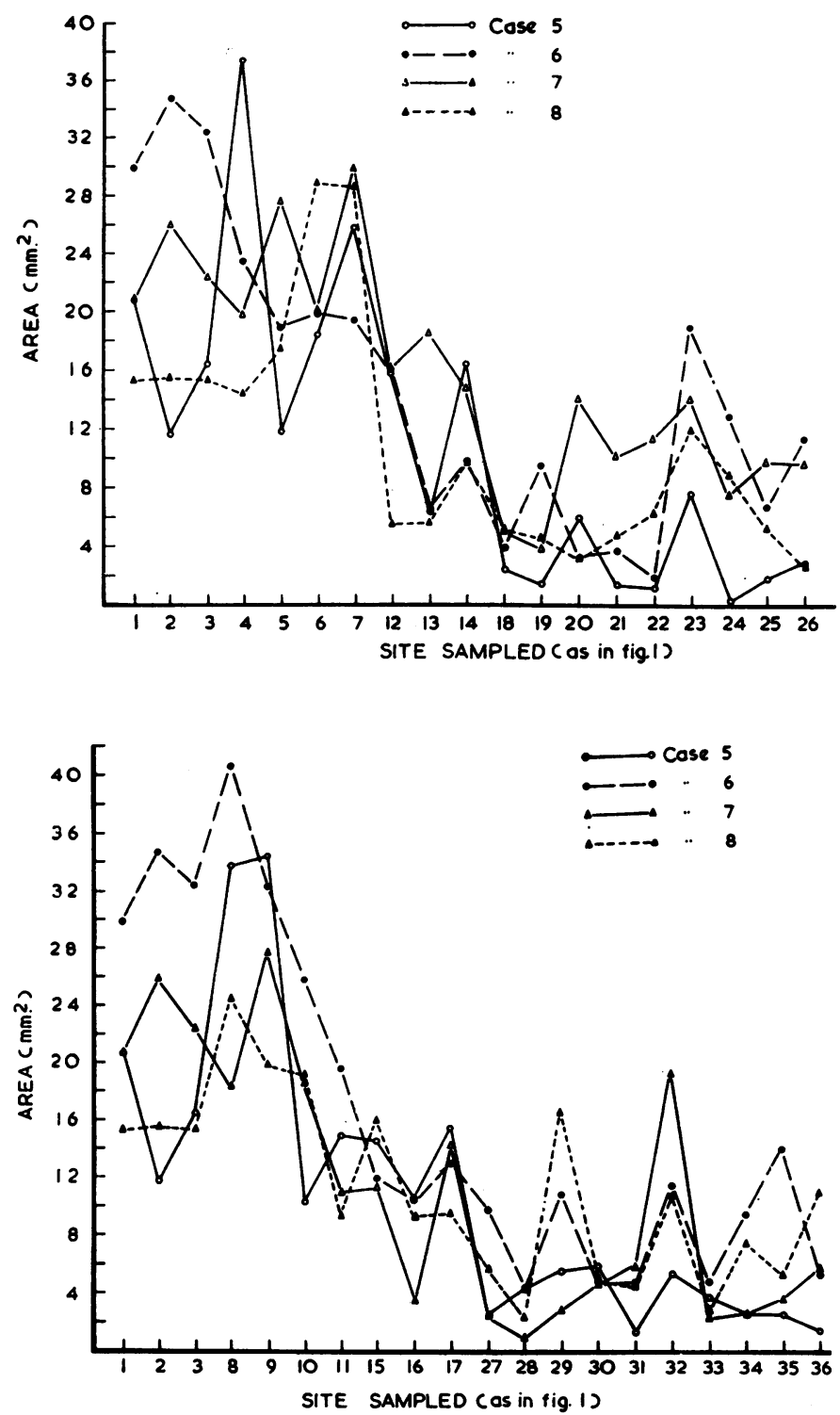

FIG. 4. Graph showing areas of glands at various sites in the trachea and bronchi of the lung in four bronchitics: (above) the left lung; (below) the right lung.

further bronchial divisions beyond the segmental bronchi. Also, we have shown that the gland areas were increased more proportionately ${ }^{2}$ in the segmental bronchi than in others in chronic bronchitis (Fig. 6A and B).

2 The difference of $\log$ values between controls and bronchitics is related to the $\log$ of their ratio.
The greater increase in gland area in bronchitis in the left segmental bronchi than in the right was statistically significant. Normally, the total area of glands in those bronchi was greater on the right than on the left, but in chronic bronchitis it was equal on the two sides. We are unable to assess the practical importance of this finding.

Chronic bronchitis appears to be associated with the inhalation of irritating substances, as in atmospheric pollution and cigarette smoking. Our finding of the wide extent of mucous gland enlargement in chronic bronchitis would be consistent with such an association. Reid (1960a) was able to produce hypersecretion of bronchial mucus in rats exposed to sulphur dioxide fumes. Micro-organisms probably play some part in maintaining hypersecretion of mucus between exacerbations of infection, but there is little histological evidence of infection of the bronchial mucosa except in greatly dilated bronchi.

\section{SUMMARY}

A quantitative method was used to obtain the area of mucous glands in transverse sections of bronchi; 36 sites were sampled from the trachea and main, lobar, and segmental bronchi.

In addition to confirming our previous observation that the glands were usually larger in bronchitics, we have shown that all the above sites were usually involved to some extent, but that the enlargement of the glands was not uniform along the tracheo-bronchial tree.

There was a proportionately greater increase in gland area in the segmental bronchi, especially of the left lung, than in other sites in chronic bronchitis.

The main bronchi showed a greater actual increase in area of glands than elsewhere in chronic bronchitis.

The lowermost readings at nearly all sites in bronchitics overlapped the uppermost readings in 


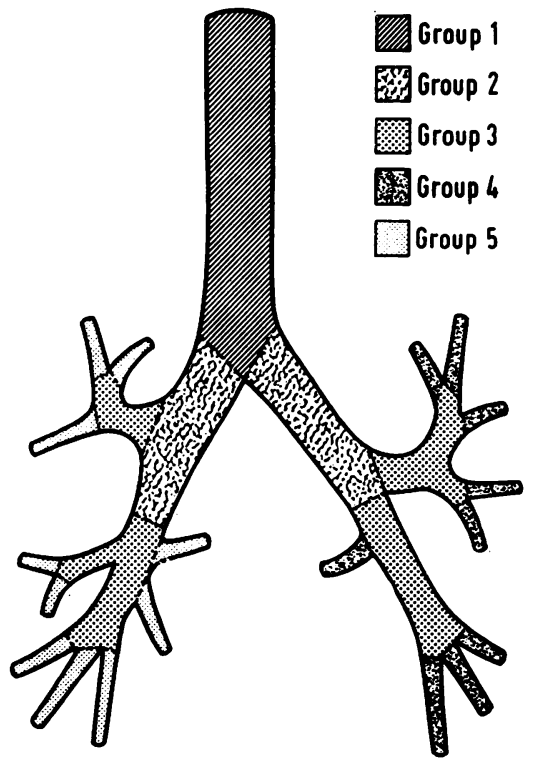

FIG. 5. Diagram showing five groups of sites compared statisticclly.

FIG. 6. Grophs relevant to the analysis of groups illustrated in Figure 5: (A) group 4 shows a significantly higher difference between the mean logarithms of weights of bronchitics and controls; $(B)$ mean logaritlm of weights of each group of sitcs. Notice that group 4, where the glands weigh the least, showed the greatest difference in A; (C) differences in mean actual areas between bronchitics and controls. Group 2 represents the main bronchi on both sides.

controls. As a result, chronic bronchitis could not always have been diagnosed on one measurement alone.

The overall pattern of gland enlargement reported here is consistent with the view that inhaled irritants are of great importance in the aetiology of chronic bronchitis.

We wish to thank Professor C. V. Harrison for his advice and encouragement and Mr. N. W. Please of University College, London, for considerable help with the statistical analysis and Table III. We also
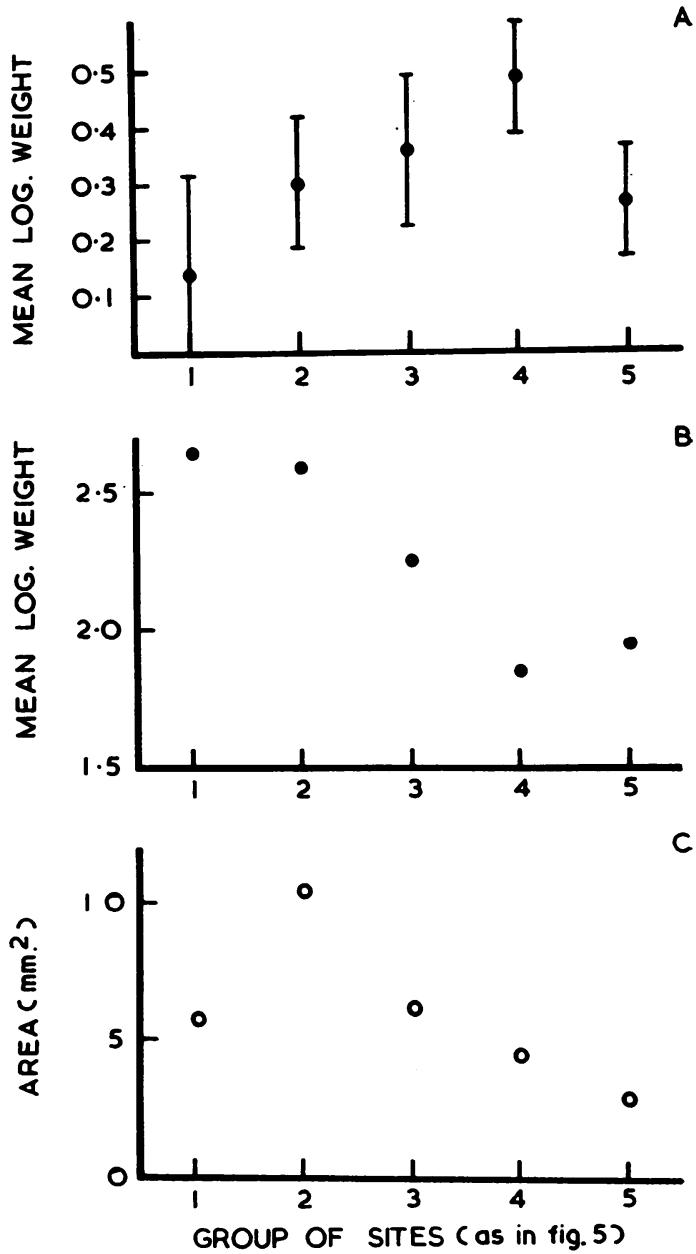

thank Mr. Ian Hunter and Miss E. M. Carroll for the histological preparations, and Mr. D. Banks for the diagrams.

\section{REFERENCES}

Ciba Guest Symposium (1959). Terminology, definitions, and classification of chronic pulmonary emphysema and related conditions. Thorax, 14, 286.

Heard, B. E. (1960). Pathology of pulmonary emphysema: methods of study. Amer. Rev. resp. Dis., 82, 792.

Reid, L. (1960a). Chronic bronchitis and hypersecretion of mucus Lectures on the Scientific Basis of Medicine, 1958-59, 8, 235 Athlone press, London.

(1960b). Measurement of the bronchial mucous gland layer; a diagnostic yardstick in chronic bronchitis. Thorax, 15, 132.

Restrepo, G., and Heard, B. E. (1963). The size of the bronchial glands in chronic bronchitis. J. Path. Bact., 85, 305. 